Meltem

İzmir Akdeniz Akademisi Dergisi

No. 2, Kış 2017, 86-90, DOI 10.32325/iaad.2017.32

\title{
Yuga, My Yuga: Misafir İşçi Hikâyeleri Sergisi
}

\section{Aylin Kuryel*}

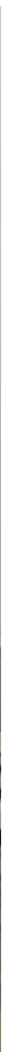

1960'lardan itibaren Türkiye'den Avrupa'ya giden işçilerin deneyimlerini en keskin ve akılda kalıcı şekilde anlatan filmlerden birisi Tunç Okan'ın 1975 yapımı Otobüs filmidir. Film, bir göçmen kaçakçısı tarafından kullanılan ve bir grup iş̧̧iyi Türkiye'den Stockholm'e taşıyan mavi bir otobüste başlar. Otobüsün içindeki göçmenlerin gözlerinden, o gözlerin gördüğü yeni şehir manzaralarına hızlı geçişler yapar yönetmen. Bu görsel taktiklerle, yeni bir yeri algılama deneyiminin parçalılığını, kurulu kimliği parçalayııı yapısını, yer değiştirmenin bedensel ve duygusal olarak yarattığı sarsıntıları güçlü bir şekilde hissettirir. Kaçakçı, göçmenlerin para ve pasaportlarını alıp ıslık çalarak toz olduktan sonra "misafir" veya "konuk işçi" olarak tabir edilen insanların deneyiminin bir metaforu olabilecek kadar güçlü bir imge ila baş başa kalıırz: Stockholm'ün ortasında, kalabalık bir meydanda, içi ne yapacağını bilmeyen erkek göçmenlerle dolu mavi bir otobüs. Şehrin içinde bir şehir, ev ile evsizlik arasında bir alan, bilinmeyen ile sınırı kırılgan, kapalı perdeleri açıılığı anda her iki tarafı birbirine ifşa etmesi an meselesi olan hem koruyucu bir ev hem de içindekilerin illegal varlıklarını şehre bağıran mavi bir kütle.

Nurdan Gürbilek Ev Ödevi kitabında, Gaston Bachelard'ın bahsettiği, koruyucu sınırları ile mutluluğun ve anıların mekânı olan ve pencereden sızan ışığı ile dışarıyı, dışarıdaki karanlığı

*Amsterdam Üniversitesi, Beşeri Bilimler Fakültesi 
gözetleyen "ev"in karşısına, dışarısı tarafından gözetlenen ve aslen kendisi karanlık olan ev imgesini koyar. Mavi otobüs, bu ikisi arasında salınır sanki. Filme de ismini veren, bir Batı Avrupa şehrinin ortasında yer alan bir getto gibi, hem koruyan, korurken içindekileri dış dünyadan ayıran ve aynı zamanda varlıklarını ifşa eden otobüs, sadece bir metafor olmaktan öte filmin baş kahramanı gibidir. Film hikâyenin ucunu açık bırakır. Peki otobüsten çıkabilen ve şehre karışabilenler, oraya yerleştikten, "gerçek bir ev"in içine girdikten sonra ne olur?

Belgrad Yugoslav Tarih Müzesi'nde 15 Aralık 2016’da açılan ve Mayıs 2017 sonuna kadar devam eden Yuga, my Yuga: Gastarbeiter stories (Yuga, benim Yugam: Misafir İşçi Hikâyeleri” adlı sergi, tam da bu soruyu soruyor ve çok çeşitli cevaplar veriyor. 1960'lardan itibaren Almanya ve Avusturya'ya giden Yugoslav işçileri konu edinen sergi, Yugoslavya'nın Avusturya ile 1966'da, Almanya ile 1968'de imzaladığı iş gücü istihdam etme anlaşmalarının 50. yılı dolayısıyla başlatılan ve bu tarihe dönüp bakmayı hedefleyen daha geniş bir araştırmanın parçası olarak tasarlanmış.

Sergi, başta Aleksandra Momčilović Jovanović, Tatomir Toroman ve Ljubomir Bratić olmak üzere, çeşitli küratör, antropolog, felsefeci ve aktivistlerin yer aldığı büyük bir ekip tarafından hazıılanmış ve Sırbistan Kültür Bakanlığı, Avusturya Kültür Forumu ve Goethe Enstitüsü tarafından desteklenmiş. Amacını, Yugoslavya'nın ekonomik ve kültürel yaşamındaki rolleri her nasıısa şimdiye dek derinlemesine irdelenmemiş "misafir iş̧̧iler"in tarihlerini tartışmaya açmak olarak belirlemiş sergi. Serginin giriş yazısında vurgulandığı üzere, sosyalizm ile kapitalizm, Doğu ile Batı, köy ile şehir ve Balkanlar ile Avrupa arasında gidip gelen işçiler söz konusu. Gidip gelirken bu ikiliklerin her iki tarafında da değişim yaratma potansiyeline sahipler ve yaratıyorlar da. Genelde küçük ve kırsal bölgelerden, Batı Avrupa’nın endüstriyel bölgelerine giden işçilerin bu yer değiştirme sonucunda alışkanlıkları ve kültürel kodları değişiyor. Bu değişimler, ilişkilerini hiçbir zaman tamamen koparmadıkları eski bağlamlarını de etkiliyor haliyle. Bir yandan da yerleştikleri yerlerde, sadece ekonomik değil aynı zamanda kültürel dönüşümlere yol açıyorlar. İşte tam da büyük tarihsel olay ve dönemeçlere tabi bir tarih yazımının gözünden kaçabilecek bu gündelik hayat arşivine bakıyor Yuga my Yuga.

Yugoslav işçilerin 1960'larda başlayan ve 1970'lerde doruk noktasına ulaşacak şekilde kitlesel olarak başka ülkelere çalışmaya gittikleri dönemin üzerinden on yıllar geçmişken, üstelik de o dönemde terk ettikleri ülke, Yugoslavya, artık yokken bu tarihin izini sürmek, ancak farklı zaman ve coğrafyalarda kalmış izleri bir araya getirerek mümkün olabilir. Tam da bunu yapan sergi, giriş yazısında şöyle diyor:

Yabancı işçi, bir doktora tezinin konusu olabileceği gibi, folk şarkılarının veya evimize gelmiş bir tesisatçı ile yaptığımız sohbetin de konusu olabilir. Etkileyici bir sanat eserinin ana teması olabileceği gibi Facebook duvarında bir ileti olarak da karşımıza çıkabilir. Kendi ailemizin tarihi kadar yakın veya resmi arşivlerdeki bilgiler kadar uzak olabilir.

Serginin kavramsal çerçevesinde dört bir tarafa saçılmış bu izleri, unutulmuş, kaybedilmiş veya önemsiz addedilmiş çeşitli parçaları kamuya açma amacının güdüldüğü belirtiliyor. Gerçekten de ana akım medyadaki göçmen işçi temsillerinden yabancı iş̧̧ileri konu edinen filmlere, bit pazarında bulunan objelerden iş̧̧ilerin kendi deneyimlerini aktardıkları videolara uzanan arşiv Yugoslav yabancı iş̧̧i konusunu sosyal, politik ve kültürel olarak irdelemek, ayrıca duygusal boyutlarına dair fikir edinmek için zengin bir kaynak sağlıyor. Kendi ülkelerinin dışında çalışan işçiler için nelerin önemli hale geldiğine, sosyal hayatlarını bulundukları ülkede kurma aşamasında geldikleri yeri mikro düzeylerde var etmeye çalışarak hangi melez formlara ulaştıklarına ışık tutuyor. Tito'nun sosyalist Yugoslavya'sından yola çıkıp kapitalist Batı Avrupa'da ucuz iş gücü olarak istihdam edilen insanların ekonomik, kültürel ve duygusal dünyalarına ustalıkla kapı aralıyor.

Kapıdan girdik. İçinden henüz biri çıkmış gibi görünen dağınık bir oda. Elektrikli ocakta tencereler, birkaç votka şişesi, dolaba dayanmış kızaklar ve dolapta asılı bir futbol takımı üniforması. 1970’lerin küçük televizyonlarından biri, çiçekli plastik masa örtüsünün üzerinde duruyor; masada bir radyo ve saçılmış kağılır. Yarı yarıya toplanmış bir yatak ve bir bisiklet. Dolabın üstüne yerleştirilmiş büyük, sağlam bir valiz; odadaki diğer her şeyin üzerindeki konumundan odayı süzüyor. 


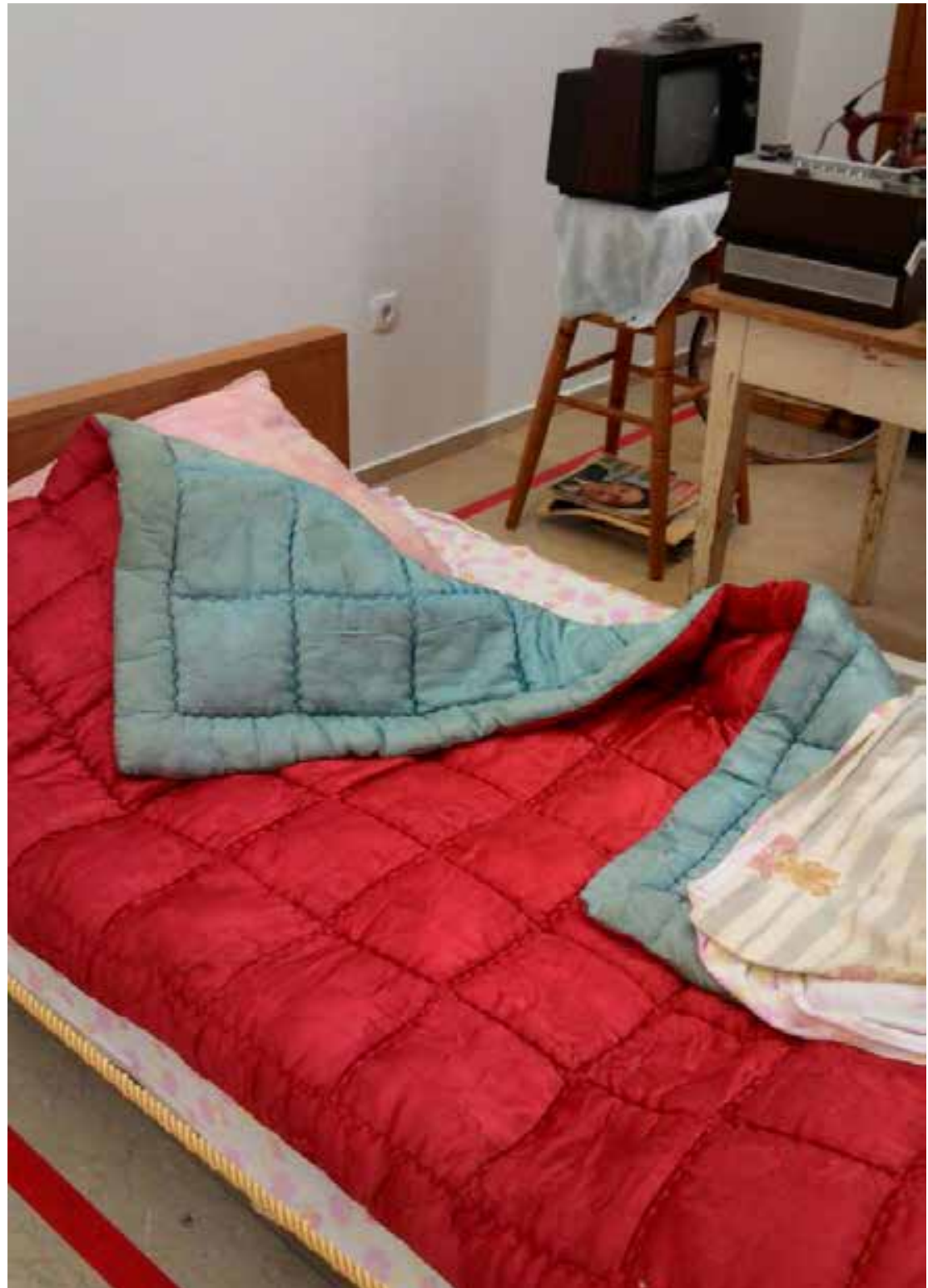

Yorganım memleketten

Sanki isterse tüm bu odayı içine alabilecek gibi görünüyor valiz. Bir yandan da her an orayı terk etmeye olanak verecek gibi. Odayı kendisinden doğru okumaya zorluyor bakanı. Bu, 1970’lerde Yugoslavya'dan Batı Avrupa'ya çalışmaya gitmiş bir işçinin odası. Arşiv taraması ve sözlü tarih ile oluşturulmuş bu prototip göçmen işçi odası, serginin tarihe gündelik hayat ve objeler üzerinden bakma tercihini yansıtan parçalardan biri. İçindeki kişinin yeni terk etmiş gibi göründüğü bu odaya bakarken karışık fikir ve duygulara kapılıyor insan: Tarih bu şekilde daha henüz yaşanmış gibi canlandırılabilir mi? Bu aslında onu dondurma riski taşımaz mı? Gündelik sahneler aslında bilmediğim bir deneyimi biliyormuşum gibi bir his mi uyandırıyor? İznim olmayan bir yere mi bakıyorum? 
Nostaljinin tarihi düşünmedeki rolü ne? Ben bu odaya bakarken, Tunç Okan’ın mavi otobüsünü dışarıdan gözleyen polise mi, yoksa içeride perdeleri kapatmış oturan kaçak göçmene mi yakın duruyorum? Misafir ne demek ve burada misafir olan kim?

Serginin misafir iş̧̧ileri kendi tarihlerini yazan öznelere dönüştürme çabası, okunan metinler, duyulan sesler, görülen fotoğraf ve objeler artıkça daha da iyi işlemeye başlıyor. İzleyici üç farkı bölüm arasında mekik dokuyor: Izler, Insanlar, Kendi Tarihini Yazma (self-historicization). Izler bölümü, unutulmuş, kıyıda köşede kalmış, önemsiz addedilmiş ve arşivlerin tozlu bölmelerine itilmiş ve hatta bit pazarlarında son bulmuş belge ve objeleri bir araya getiriyor. İnsanlar bölümünde, misafir işçilerin kişisel eşyaları, anılan oda gibi yaşam birimleri ve yokluk ile başarı, gurbet ile heves arasında gidip gelen görsel ve sesli belgeler yer alıyor. Üçüncü ve son olarak, Yugoslav İşçi Kulüpleri ve dönemin sosyal hayatı üzerine belge toplamış kişilerin arşiv ve sergi çalışmalarından parçalar içeren Kendi Tarihini Yazma bölümü, serginin öznelerinin kendi sözlerini üretme, kendi tarihlerini yazma fikrini oldukça güçlendiriyor.

Her bölümde ortak olan, gündelik hayat anlatılarının ve işlevli, işlevsiz gündelik objelerin kapladığı ağırııkı alan. Kilimler, kül tablaları, posterler, dergi kapakları, fotoğraf makineleri, kıyafetler, süs eşyaları, Nikola Babic'in Crazy Days filmi gibi göçmen deneyimi temasını işleyen filmler, göçmenlerin gittikleri yerlerde çıkardıkları plaklar. Yabancı iş̧̧iler arasında, sistematik olarak bir şeyler toplayanların sayısının hiç de az olmadığını görüyoruz. Bazı objeler, en basit tanımlarıyla sergileniyorlar. Örneğin, Almanya'da henüz yokken Yugoslavya'dan oraya video kamera götürmüş olan bir göçmenin videosu "Kamera: Dünya üzerinde yolculuk yaparken vazgeçilmez bir malzeme" olarak tanıtılıyor. Böylelikle objeyi biz de ilk defa görmüş gibi oluyor, onun ilk yolculuklarında yarattığı hevesi hissediyoruz. Objeler bir bir gözümüzün önünden geçerken, bir yandan da gündelik ve sıradan olanı dışlayan bir tarih yazımının sınırları ihlâl ediliyor.

Göçmen iş̧̧inin konumu, öznenin kendi tarihini kendisinin yazması fikrini geliştirmek, bunun yöntemlerini tartışmak ve bulmak-bir araya getirmek-sergilemek üçgeninin nasıl genişletilebileceği üzerine kafa yormak için verimli bir örnek sunuyor aslında. Resmî tarihe dahil olmayan insanIarın kenara çekilmeyi reddetmesi ve kendi tarihlerini yazması tarihe bakışı değiştirebileceği gibi bugünü kurma şekillerini de derinden etkileyebilir sonuçta. Göçmen işçilerin kendileri hakkında konuştukları, yazdıkları ve yarattıkları alanları görünür kılan sergi, tarihin kendi içinde homojen olmayan bu engebeli yapısını gözler önüne seriyor. İzleyicinin konumuna göre de değişebilecek şekilde bir hatırlama edimi başlıyor; kolektif hafıza canlanıyor. Bugün bu alanların nasıl kurulduğu ve kurulacağı sorusu da baki kalıyor.

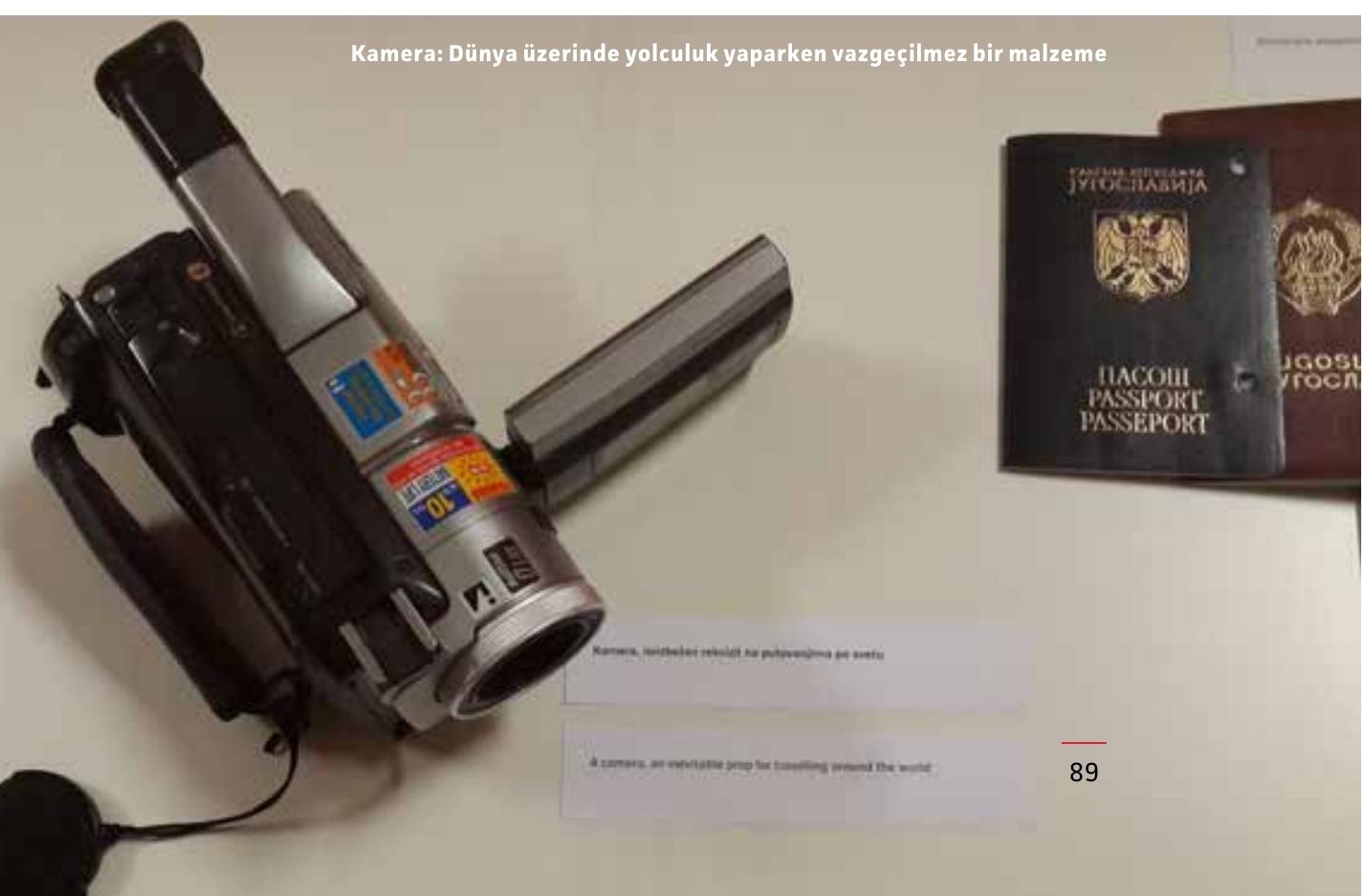


Yugoslav misafir işçilere özgü deneyimlere bakarken, farklı coğrafyalarda benzer deneyimleri hatıllatan, coğrafya ve dönemleri kesen bir şekilde yer değiştirme, yerleşme, unutma, öğrenme, ev ve evsizlik kavramları, misafirlik, işçi olma ve yoksulluk deneyimleri üzerine düşündürebilen bir sergi Yuga, my Yuga. Türkiye'de de benzer konulara değinen iki sergi gerçekleşti yakın dönemde. Haziran 2016'da SALT Galata'da, Almanya'dan Türkiye'ye dönmüş misafir işçilerin inşa ettiği ev ve apartmanlara eğilen "Göçebe Mekânlar" sergisi açılmıştı. Biriktirilen kültürel deneyim ve kodların mekân kurmadaki etkisine, çocukluk anıları, Almanya'dan taşınan deneyimler ve gelecekten beklentilerin bir araya gelerek mekânsal tercihleri belirlemesine bakan bu sergiden sonra, Mart 2017'de DEPO'da “Sıla Yolu: Türkiye Tatili Yolu ve Otoban Hikâyeleri” adı bir sergi açıldı. Bu sergi, 1960'lardan beri Türkiyeli göçmenler tarafından sıkça kullanılan Almanya ve Türkiye arasındaki, Sıla Yolu, Ölüm Yolu ya da Autoput da denilen E5 karayoluna odaklanıyor. Malve Lippmann ve Can Sungu'nun E5 karayolu üzerindeki ve arşivlerdeki gezintileri sonucunda topladıklarını, göçmen ailelerin en favori arabalarından biri olan 85 model Ford bir minibüsün içine yerleştirdikleri sergi, aynı güzergâhın bugün Batı Balkan rotası olarak Batı Avrupa'ya ulaşmaya çalışan mülteciler tarafından da ters yöne doğru kullanıııı̆ını hatırlatarak mekâna bakışı katmanlandıııyor. 